\title{
Low-cost, easy-to-build noninvasive pressure support ventilator for under-resourced regions: open source hardware description, performance and feasibility testing
}

\author{
Onintza Garmendia ${ }^{1,2}$, Miguel A. Rodríguez-Lazaro ${ }^{1}$, Jorge Otero ${ }^{1,3}$, \\ Phuong Phan ${ }^{4}$, Alexandrina Stoyanova ${ }^{5}$, Anh Tuan Dinh-Xuan (106 ${ }^{6}$, David Gozal (107, \\ Daniel Navajas ${ }^{1,3,8}$, Josep M. Montserrat ${ }^{2,3,9}$ and Ramon Farré , $^{1,3,9}$
}

@ERSpublications

Patients in under-resourced areas cannot be treated by mechanical ventilation given the unaffordable cost of conventional devices; here a low-cost, easy-to-build ventilator with open access details for free replication is designed and tested https://bit.ly/34UcbWp

Cite this article as: Garmendia O, Rodríguez-Lazaro MA, Otero J, et al. Low-cost, easy-to-build noninvasive pressure support ventilator for under-resourced regions: open source hardware description, performance and feasibility testing. Eur Respir J 2020; 55: 2000846 [https://doi.org/10.1183/ 13993003.00846-2020].

\section{ABSTRACT}

Aim: Current pricing of commercial mechanical ventilators in low-/middle-income countries (LMICs) markedly restricts their availability, and consequently a considerable number of patients with acute/chronic respiratory failure cannot be adequately treated. Our aim was to design and test an affordable and easy-tobuild noninvasive bilevel pressure ventilator to allow a reduction in the serious shortage of ventilators in LMICs.

Methods: The ventilator was built using off-the-shelf materials available via e-commerce and was based on a high-pressure blower, two pressure transducers and an Arduino Nano controller with a digital display (total retail cost $<75$ USD), with construction details provided open source for free replication. The ventilator was evaluated, and compared with a commercially available device (Lumis 150 ventilator; Resmed, San Diego, CA, USA): 1) in the bench setting using an actively breathing patient simulator mimicking a range of obstructive/restrictive diseases; and b) in 12 healthy volunteers wearing high airway resistance and thoracic/abdominal bands to mimic obstructive/restrictive patients.

Results: The designed ventilator provided inspiratory/expiratory pressures up to $20 / 10 \mathrm{cmH}_{2} \mathrm{O}$, respectively, with no faulty triggering or cycling; both in the bench test and in volunteers. The breathing difficulty score rated $(1-10$ scale) by the loaded breathing subjects was significantly $(p<0.005)$ decreased from $5.45 \pm 1.68$ without support to $2.83 \pm 1.66$ when using the prototype ventilator, which showed no difference with the commercial device $(2.80 \pm 1.48 ; \mathrm{p}=1.000)$.

Conclusion: The low-cost, easy-to-build noninvasive ventilator performs similarly to a high-quality commercial device, with its open-source hardware description, which will allow for free replication and use in LMICs, facilitating application of this life-saving therapy to patients who otherwise could not be treated.

This article has an editorial commentary: https://doi.org/10.1183/13993003.01271-2020

This article has supplementary material available from erj.ersjournals.com

Received: 25 March 2020 | Accepted after revision: 08 April 2020

Copyright OERS 2020. This version is distributed under the terms of the Creative Commons Attribution NonCommercial Licence 4.0. 


\section{Introduction}

Noninvasive mechanical ventilation (NIV) is a widely used and accepted treatment for chronic respiratory diseases and, in some cases, it is also an alternative to invasive ventilation options for patients with acute respiratory failure caused by a variety of aetiologies [1]. Although positive pressure ventilation in low- and middle-income countries (LMIC) is most frequently provided invasively, the benefits of NIV are being increasingly recognised. Indeed, for obvious reasons of cost and ease of use, NIV appears to be not only an effective, but also a particularly suitable approach to provide respiratory support in patients living in developing low-income economies [2]. This is especially relevant since in these regions the burden of critical illness is large, and is expected to increase with growing urbanisation, emerging epidemics and expanding access to hospitals [2]. Furthermore, the elevated cost of healthcare staffing, infrastructure needs and onerous access to supplies have hampered the development of fully equipped intensive care units in LMICs [3]. As a consequence, the demand for cost-effective medical equipment, such as mechanical ventilators, is likely to greatly increase in those countries. Moreover, mechanical ventilators are costly, which markedly restricts their availability and, consequently, the ability to adequately treat a significant number of patients with both acute and chronic respiratory failure in LMICs. These issues are all the more evident in light of the ongoing coronavirus pandemic, where even industrialised economies are encountering significant shortages in the number of available ventilators to meet the demands imposed by this disease, such that availability of noninvasive respiratory support may be valuable for certain patients or as a temporary bridge $[4,5]$.

Philanthropic donation of medical devices may help in providing mechanical ventilators to non-resourced regions in LMICs, but these initiatives are fraught with considerable limitations. Indeed, donation of commercially available equipment is expensive and is only partially effective since it has been reported that up to $50 \%$ of donated devices become unusable due to lack of adequate maintenance and inability to obtain spare parts [6]. In addition, donations are hardly sustainable because they require long-term commitments, e.g. to provide device servicing. In this context, alternative solutions that are based on in-house manufacturing of pressure support devices $[7,8]$ could reduce the serious shortage of ventilators in LMICs. Accordingly, the aim of this study was to design and test a novel low-cost bilevel pressure support ventilator, and provide open access to the detailed technical information, thereby allowing for free and unrestricted replication and implementation. To ascertain adequate performance of the device, bench testing was carried out based on simulated patients with obstructive/restrictive diseases under well-controlled conditions, a common widely accepted approach to test therapeutic devices for respiratory support [9-18]. Then, and following the existing literature [19-21], the prototype ventilator was tested in healthy volunteers subjected to obstructive-restrictive loaded breathing to mimic patients with respiratory diseases requiring NIV.

\section{Methods}

\section{Ventilator description}

The ventilator was designed to be affordable and easy-to-build, providing an open-source hardware description to allow free replication. The prototype was built using off-the-shelf materials available via e-commerce: a high-pressure blower and its driver (WM7040; Ning Bo Feng Hua Wei Cheng Motor Factory, Zhejiang, China), two pressure transducers (XGZP6847005KPG; CFSensor, Wuhu, Anhui, China) and an Arduino Nano controller with a digital display. Pressure and flow were continuously measured at the outlet of the ventilator and fed into the controller which was provided with a custom-made code to detect inspirations and expirations and to accordingly trigger the inspiratory and expiratory pressures generated by the blower. The ventilator can operate in timed or spontaneous timed mode (spontaneous breaths of patients are assisted and if the patient's effort is not detected a timed breath is triggered according to a rescue frequency). The retail cost of this ventilator prototype was $<75$ USD, and includes all required electronic circuits and power source. Of note, this cost could be considerably reduced by wholesale purchasing. All the technical information and detailed circuit schematics and the controller code

Affiliations: 'Unitat de Biofísica i Bioenginyeria, Facultat de Medicina i Ciències de la Salut, Universitat de Barcelona, Barcelona, Spain. ${ }^{2}$ Sleep Lab, Hospital Clinic, Universitat de Barcelona, Barcelona, Spain. ${ }^{3} \mathrm{CIBER}$ de Enfermedades Respiratorias, Madrid, Spain. ${ }^{4}$ Hue Central Hospital, Hue, Vietnam. ${ }^{5}$ Dept of Economics, Faculty of Economics and Business, Universitat de Barcelona, Barcelona, Spain. ${ }^{6}$ Service de PhysiologieExplorations Fonctionnelles, Hôpital Cochin, Assistance Publique-Hôpitaux de Paris (AP-HP), Paris, France. ${ }^{7}$ Dept of Child Health, The University of Missouri School of Medicine, Columbia, MO, USA. ${ }^{8}$ Institute for Bioengineering of Catalonia (IBEC), The Barcelona Institute of Science and Technology, Barcelona, Spain. ${ }^{9}$ Institut d'Investigacions Biomediques August Pi Sunyer, Barcelona, Spain.

Correspondence: Ramon Farré, Unitat de Biofísica i Bioenginyeria, Facultat de Medicina i Ciències de la Salut, Casanova 143, 08036 Barcelona, Spain. E-mail: rfarredub.edu 
required to build this ventilator (including optional enclosure by conventional 3D printer) is available for release under free terms following the open-source hardware approach in the supplementary material. Figure 1 shows external and internal images of the prototype.

\section{Bench testing}

To assess the performance of the novel bilevel pressure ventilator under well-controlled conditions, the prototype was evaluated in a bench test using an active patient simulator modelling the respiratory mechanics of patients with different levels of obstructive/restrictive diseases (figure 2). The passive component of the respiratory system model was a variable resistance-compliance (R-C) lung model (Adult SmartLung; IMT Analytics, Buchs, Switzerland). To implement an active breathing model, the passive $\mathrm{R}-\mathrm{C}$ system simulating the lungs was enclosed in a cylindrical box connected to a negative pressure source (figure 2), as explained in detail in the supplementary material. Figure 3 shows examples of the simulated pleural pressures applied to the passive model to implement active patient models, which combined two breathing frequencies (15 and 20 breaths $\cdot \mathrm{min}^{-1}$ ) and three negative peak pressure amplitudes $\left(-6,-9,-12 \mathrm{cmH}_{2} \mathrm{O}\right)$. Four respiratory $\mathrm{R}-\mathrm{C}$ systems were set for testing the ventilator, mimicking a patient with mild disease, a purely obstructive patient (increased resistance), a purely restrictive patient (reduced compliance) and a patient with both obstruction and restriction (table 1). Two breathing frequencies were used and different inspiratory efforts were set according to the level of disease (table 1). As shown in figure 2, the performance of the ventilator prototype was assessed by connecting it to the patient simulator through flexible conventional tubing ( $2 \mathrm{~m}$ length, $22 \mathrm{~mm}$ diameter), including a 5 -mm diameter orifice at the nasal mask to create an intended air leak orifice to avoid rebreathing, as it is set in conventional clinical applications. The experimentally measured pressure-flow $\left(\mathrm{P}-V^{\prime}\right)$ relationship in this intended leak $\left(V^{\prime} \approx 10 \cdot \mathrm{P}^{0.48} ; V^{\prime}\right.$ in $\mathrm{L} \cdot \mathrm{min}^{-1}, \mathrm{P}$ in $\left.\mathrm{cmH}_{2} \mathrm{O}\right)$ resulted in a minimum continuous air flow renewal of $20 \mathrm{~L} \cdot \mathrm{min}^{-1}$ for a nasal pressure of $4 \mathrm{cmH}_{2} \mathrm{O}$. In addition to the intentional air leak, we eventually also included a non-intentional air leak ( $5 \mathrm{~mm}$ diameter orifice) to simulate the real-life leaks observed in patients subjected to NIV owing to poor mask fit on the patient's face (table 1). This unintended leak created air flow leaks of 30 and $40 \mathrm{~L} \cdot \mathrm{min}^{-1}$ at nasal pressure values of 10 and $18 \mathrm{cmH}_{2} \mathrm{O}$, respectively.

Therefore, the ventilator prototype was tested under 16 different simulated conditions (table 1), covering real life settings when applying NIV in clinical practice. For the sake of comparison, the same 16 bench test conditions were also applied to a high-performance commercially available mechanical ventilator (Lumis 150, VPAP ST; Resmed) (with default settings). During the tests, nasal pressure, flow and simulated pleural pressure signals were measured (figure 2) with a Fleisch pneumotachograph (Metabo, Epalinges, Switzerland) and pressure transducers (Celesco, Toronto, Canada; Validyne, Northridge, CA, USA) recorded at $100 \mathrm{~Hz}$. Subsequently, tidal volumes were digitally computed by integration of the flow signal (after adequate zero-flow correction). Inspiratory trigger delay was measured as the time from starting the decrease in negative inspiratory (simulated pleural) pressure to the time at which nasal pressure started to be positive [22].

\section{Ventilator testing in healthy volunteers}

The ventilator prototype was tested in 12 healthy volunteers (five females) recruited from the university environment. Their mean age was $32.4 \pm 5.8$ years and their mean \pm se body mass index was 23.3 $\pm 2.0 \mathrm{~kg} \cdot \mathrm{m}^{-2}$. To mimic the respiratory load corresponding to a patient requiring NIV the volunteers were instructed to increase their airway resistance and to decrease their respiratory compliance, as explained in

a)

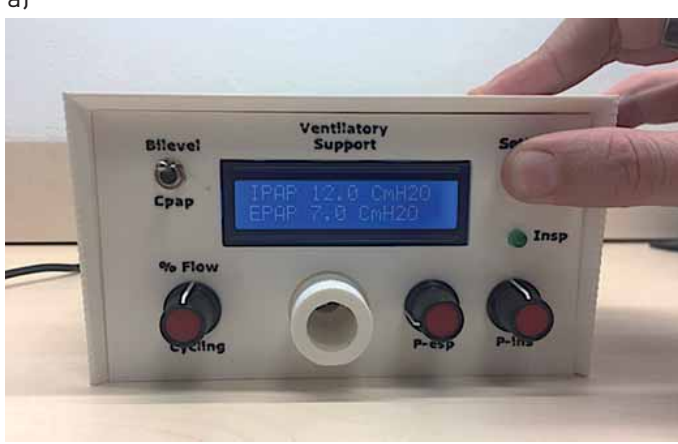

b)

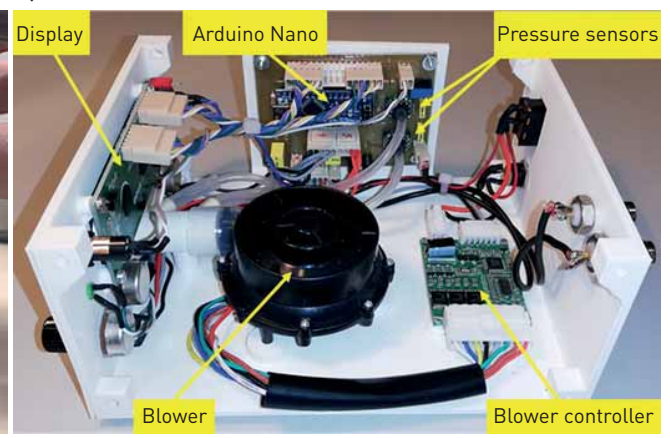

FIGURE 1 Low-cost ventilator prototype. a) Front view and b) internal view showing the main modules. 


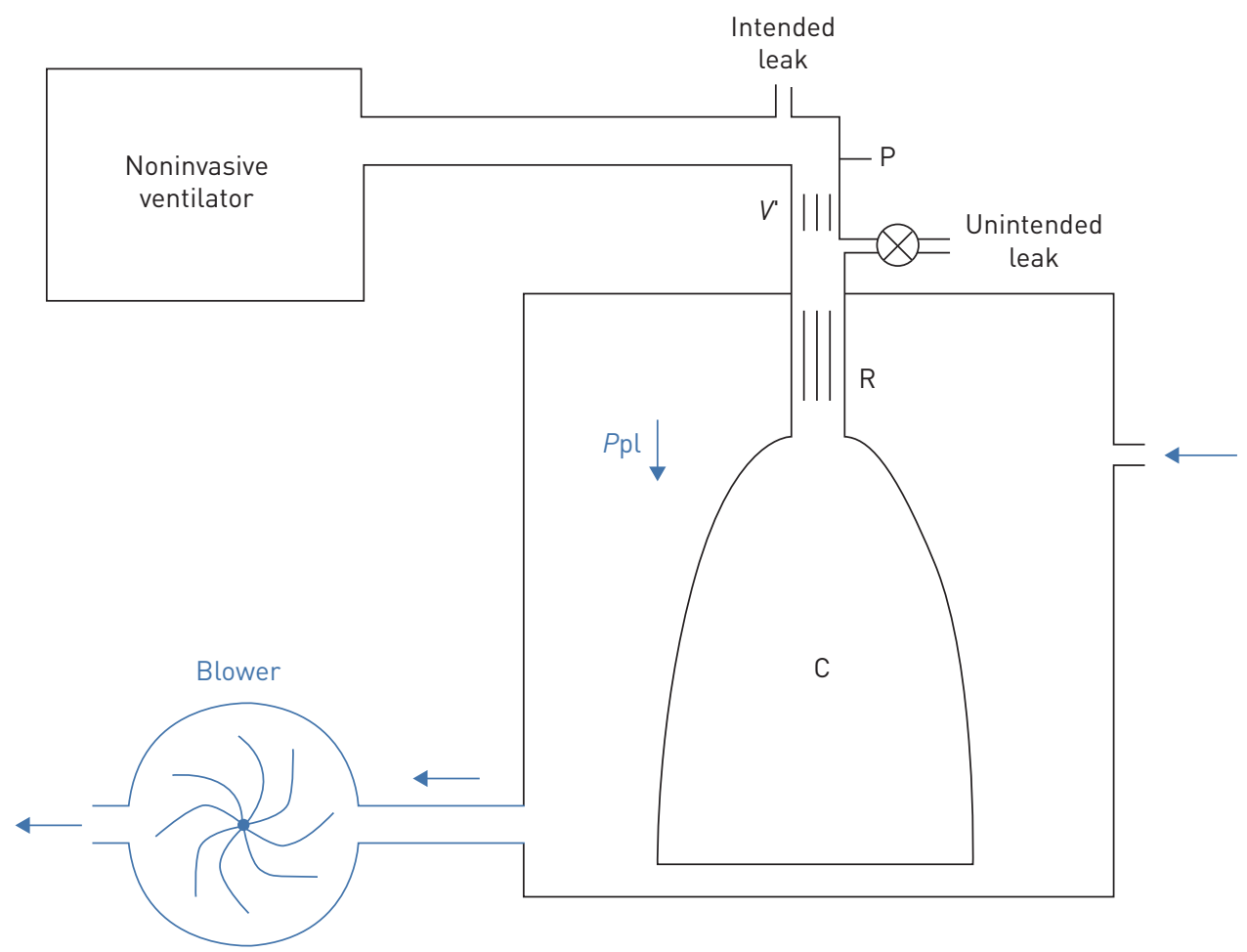

FIGURE 2 An active patient simulator to test the mechanical ventilator prototype. Passive respiratory mechanics was mimicked by a resistance-compliance (R and $C$, respectively) passive model enclosed in a box. The active component inducing breathing in the model consisted of a blower connected to the box wall. As blower flow increased, the pressure in the box (simulated pleural pressure $(P p l)$ ) progressively decreased to negative values, inducing inspiration in the R-C lung model. The active breathing model was connected to the ventilator under test by a conventional tube and a conventional intended leak to avoid rebreathing. An unintended leak allowed simulation of air leak caused by the lack of a perfect seal between the nasal mask and the patient's face. Pressure $(P)$ and flow $\left(V^{\prime}\right)$ were measured at the level of the nasal mask by means of transducers.

detail in the supplementary material. The protocol was carried out by one respiratory physiotherapist expert in NIV. The volunteer subject was sitting in a comfortable armchair and was equipped with a finger pulse oximeter for monitoring oxygen saturation (WristOx $x_{2}$, Model 3150; Nonin Medical, Plymouth, MN, USA). First, they were allowed to get familiar with the use of a nasal mask and NIV for 3 min. To this end, they were connected to a noninvasive ventilator (Lumis 150, VPAP ST) through conventional nasal mask and tubing, with inspiratory and expiratory pressures set to 8 and $4 \mathrm{cmH}_{2} \mathrm{O}$, respectively. Subsequently, the subject was equipped with the resistive and restrictive loads and breathed spontaneously (unsupported) for $2 \mathrm{~min}$. After that period of loaded breathing, the volunteer was asked to score his/her breathing discomfort sensation on a visual analogue scale where 1 would correspond to spontaneous normal breathing and 10 to the maximum breathing discomfort they could consider unbearable. Then, they were connected to a mechanical ventilator with inspiratory and expiratory pressures set to 16 and $6 \mathrm{cmH}_{2} \mathrm{O}$, respectively, in spontaneous trigger mode with a backup frequency of $12 \mathrm{breaths} \cdot \mathrm{min}^{-1}$. This ventilator was either the prototype under test or a commercially available high-performance device (Lumis 150, VPAP ST; default settings) determined at random. At the end of a 2 -min period, the subject was again asked to score their breathing discomfort and, without interruption or notice to the subject, the ventilator was shifted to the other device for $2 \mathrm{~min}$ and then the volunteer was asked again for scoring discomfort. This process of alternating the ventilator (prototype or commercial) was repeated twice more. The discomfort scoring finally assigned to each ventilator was the mean score of the three periods corresponding to each device. Any faulty triggering or cycling, as observed through inspection of the real time nasal pressure signal and subject's breathing activity, was registered by the physiotherapist.

\section{Statistics}

In the bench test, the different investigated variables were assessed by comparing the data obtained with the prototype and the commercial ventilator by means of a paired t-test. In the test with voluntary subjects, discomfort scores when the individual was not mechanically supported and when supported by 

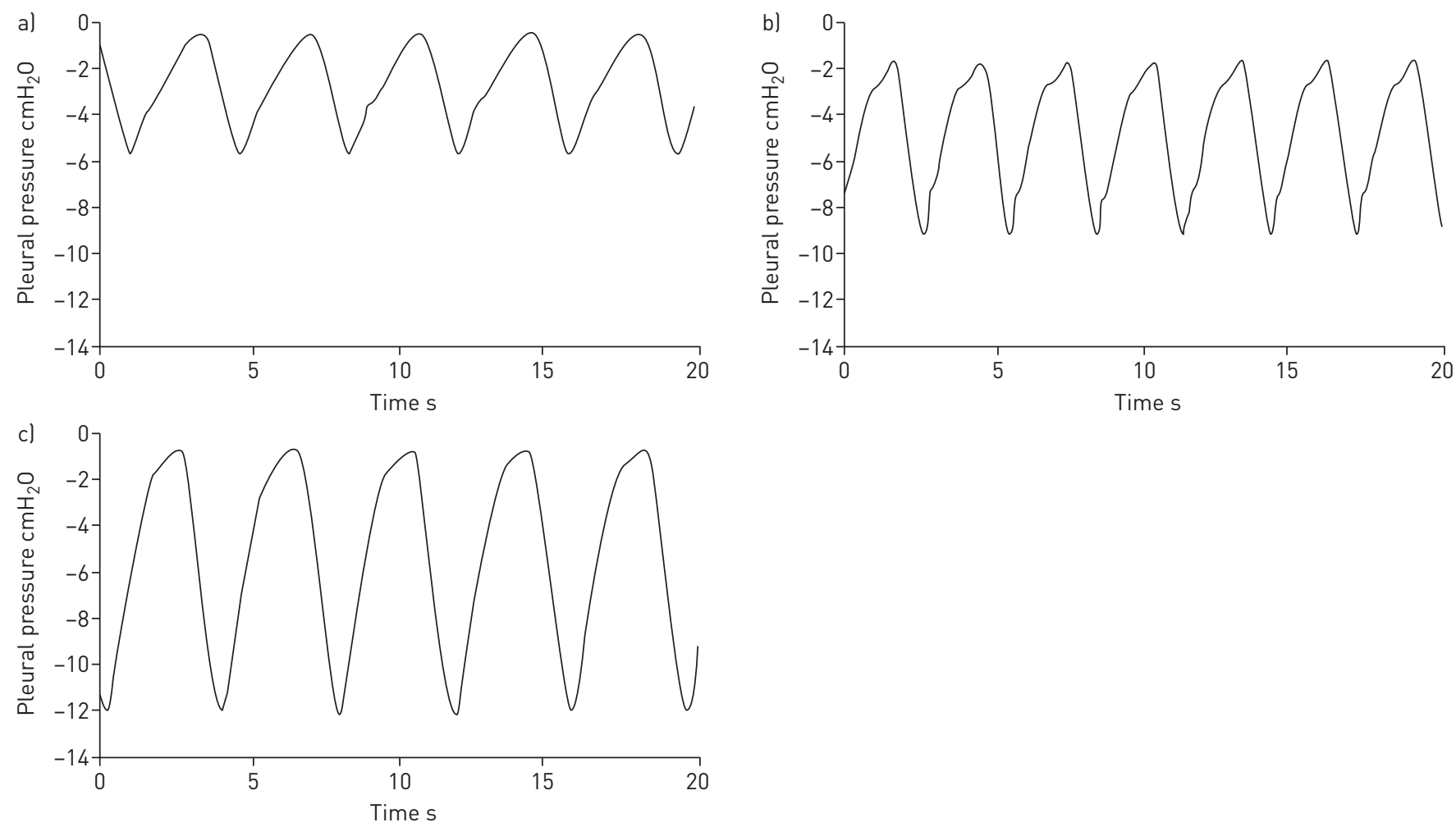

FIGURE 3 Examples of simulated pleural pressures in the bench test. a) Conditions 1 to 4 (mild), b) conditions 5 to 8 (obstructive), and c) conditions 9 to 16 (restrictive and obstructive restrictive). See table 1 for definition of conditions.

TABLE 1 Respiratory resistance-compliance systems of 16 different conditions simulated for the bench test

\section{Simulated patient}

\section{Resistance} $\mathrm{cmH}_{2} \mathrm{O} \cdot \mathrm{s} \cdot \mathrm{L}^{-1}$

\section{Compliance $\mathrm{mL} \cdot \mathrm{CmH}_{2} \mathrm{O}^{-1}$}

\section{Breathing rate breaths $\cdot \min ^{-1}$}

\section{Pleural negative peak pressure $\mathrm{cmH}_{2} \mathrm{O}$}

\section{Inspiratory/ \\ expiratory} pressure $\mathrm{cmH}_{2} \mathrm{O}$
Unintended leak at $10 \mathrm{cmH}_{2} \mathrm{O}$ $\mathrm{L} \cdot \mathrm{min}^{-1}$

\begin{tabular}{|c|c|c|c|c|c|c|}
\hline \multicolumn{7}{|l|}{ Mild } \\
\hline 1 & 5 & 30 & 15 & -6 & $9 / 4$ & $\mathrm{No}$ \\
\hline 2 & 5 & 30 & 15 & -6 & $9 / 4$ & 30 \\
\hline 3 & 5 & 30 & 20 & -6 & $9 / 4$ & No \\
\hline \multicolumn{7}{|c|}{ Obstructive } \\
\hline 5 & 20 & 30 & 15 & -9 & $10 / 5$ & $\mathrm{No}$ \\
\hline 6 & 20 & 30 & 15 & -9 & $10 / 5$ & 30 \\
\hline \multicolumn{7}{|c|}{ Restrictive } \\
\hline 9 & 5 & 15 & 15 & -12 & $14 / 6$ & No \\
\hline 10 & 5 & 15 & 15 & -12 & $14 / 6$ & 30 \\
\hline 11 & 5 & 15 & 20 & -12 & $14 / 6$ & No \\
\hline 12 & 5 & 15 & 20 & -12 & $14 / 6$ & 30 \\
\hline \multicolumn{7}{|c|}{$\begin{array}{l}\text { Obstructive and } \\
\text { restrictive }\end{array}$} \\
\hline 16 & 20 & 15 & 20 & -12 & $16 / 8$ & 30 \\
\hline
\end{tabular}

For full details refer to the main text. 
the two ventilators were compared by paired t-test for normally distributed variables and by Wilcoxon signed rank test for non-normally distributed variables. A value of $\mathrm{p}<0.05$ was considered statistically significant.

\section{Results \\ Bench testing}

Figure 4 shows an example of the nasal pressure and breathing flow signals recorded in one of the bench tests simulating a patient with mild disease for both the prototype and commercial ventilators. The pressure waveform in the commercial device was close to a square signal whereas the pressure generated by the prototype increased and decreased more smoothly. Consistently, the inspiratory flow induced by the commercial ventilator experienced a sudden increase at the beginning of inspiration, while the flow induced by the prototype increased more progressively.

The ventilator prototype performance was comparable to the commercial ventilator and provided inspiratory and expiratory pressures (up to 16 and $8 \mathrm{cmH}_{2} \mathrm{O}$, respectively) with no defective triggering or cycling when tested over the described 16 different simulated conditions. Figure S1 shows the pressure waveforms recorded in the 16 test conditions, showing that the prototype was performant in all cases (as was the commercial device) (figures not shown). Figure $5 \mathrm{a}$ is a Bland-Altman type plot illustrating the difference between measured maximum inspiratory and minimum expiratory pressures and the corresponding target values set at the ventilator control panel, respectively. Actual minimal expiratory pressures set to range $4-8 \mathrm{cmH}_{2} \mathrm{O}$ differed by $<1 \mathrm{cmH}_{2} \mathrm{O}$ from the target values, with positive and negative differences in the case of the prototype and commercial ventilator, respectively. Actual peak inspiratory pressures, set to range $10-16 \mathrm{cmH}_{2} \mathrm{O}$, were systematically higher than the target values for both ventilators, being greater (by $\approx 1.5 \mathrm{cmH}_{2} \mathrm{O}$ ) in case of the prototype ventilator. The trigger delay in the prototype showed no statistically significant differences when compared with the delay time in the commercial ventilator (figure 5b and c). Although statistically significant, the inspiratory tidal volumes achieved with both ventilators in the 16 different test conditions were similar (difference of $40 \mathrm{~mL}$ on average) (figure $5 \mathrm{~b}$ and c).

\section{Test in healthy volunteers with loaded breathing}

Testing in volunteers with resistive and restrictive loads provided positive results on the feasibility of the ventilator prototype for application in humans. As expected from healthy subjects, no decrease in oxygen saturation was observed throughout the whole test period when compared with the unsupported baseline
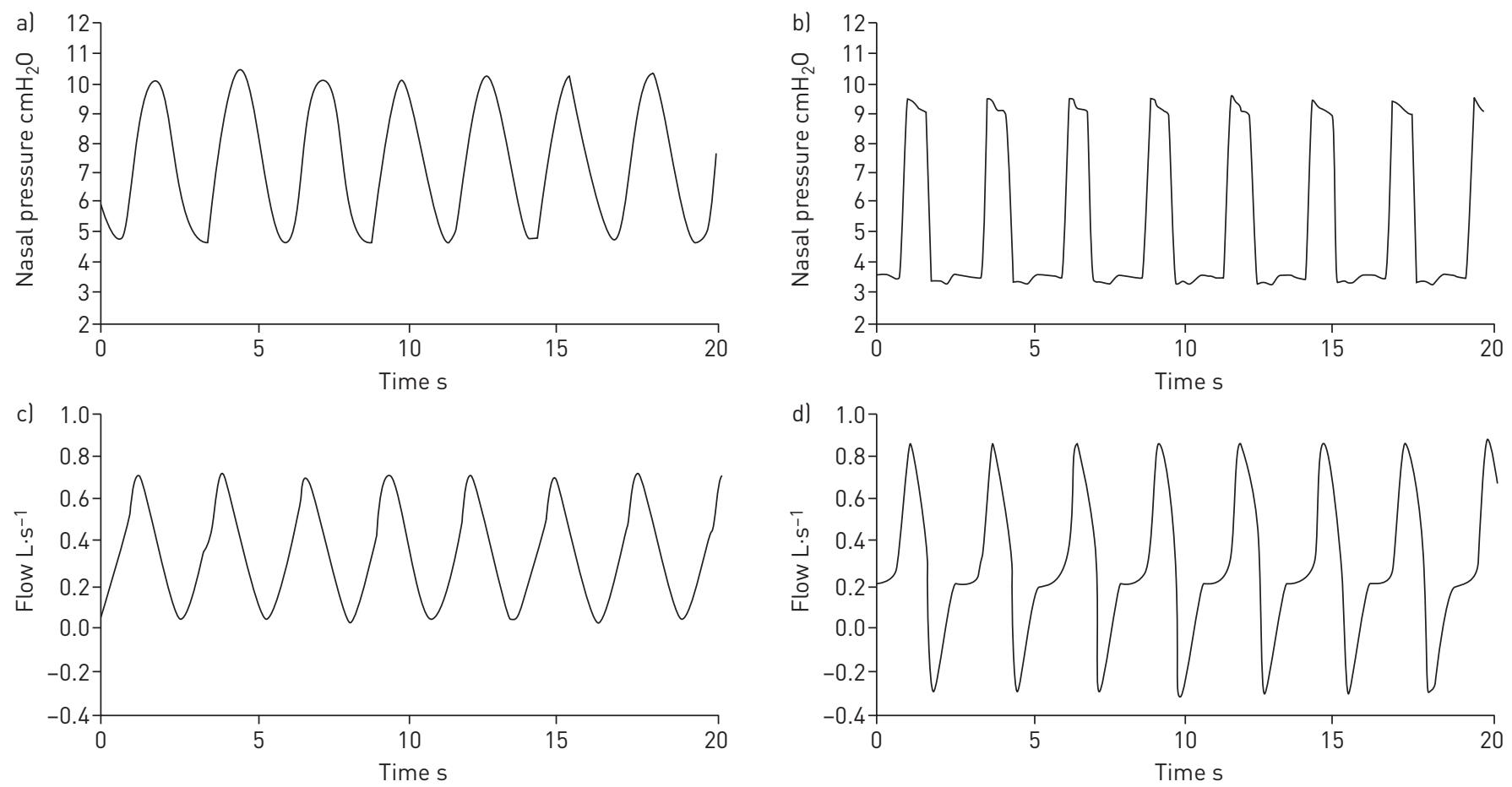

FIGURE 4 Example of the nasal pressure and breathing flow signals recorded in one of the bench tests simulating a patient with mild disease (condition 4). a, c) Prototype ventilator and b, d) Lumis 150 ventilator (ResMed, San Diego, CA. USA). See table 1 for definition of conditions. 

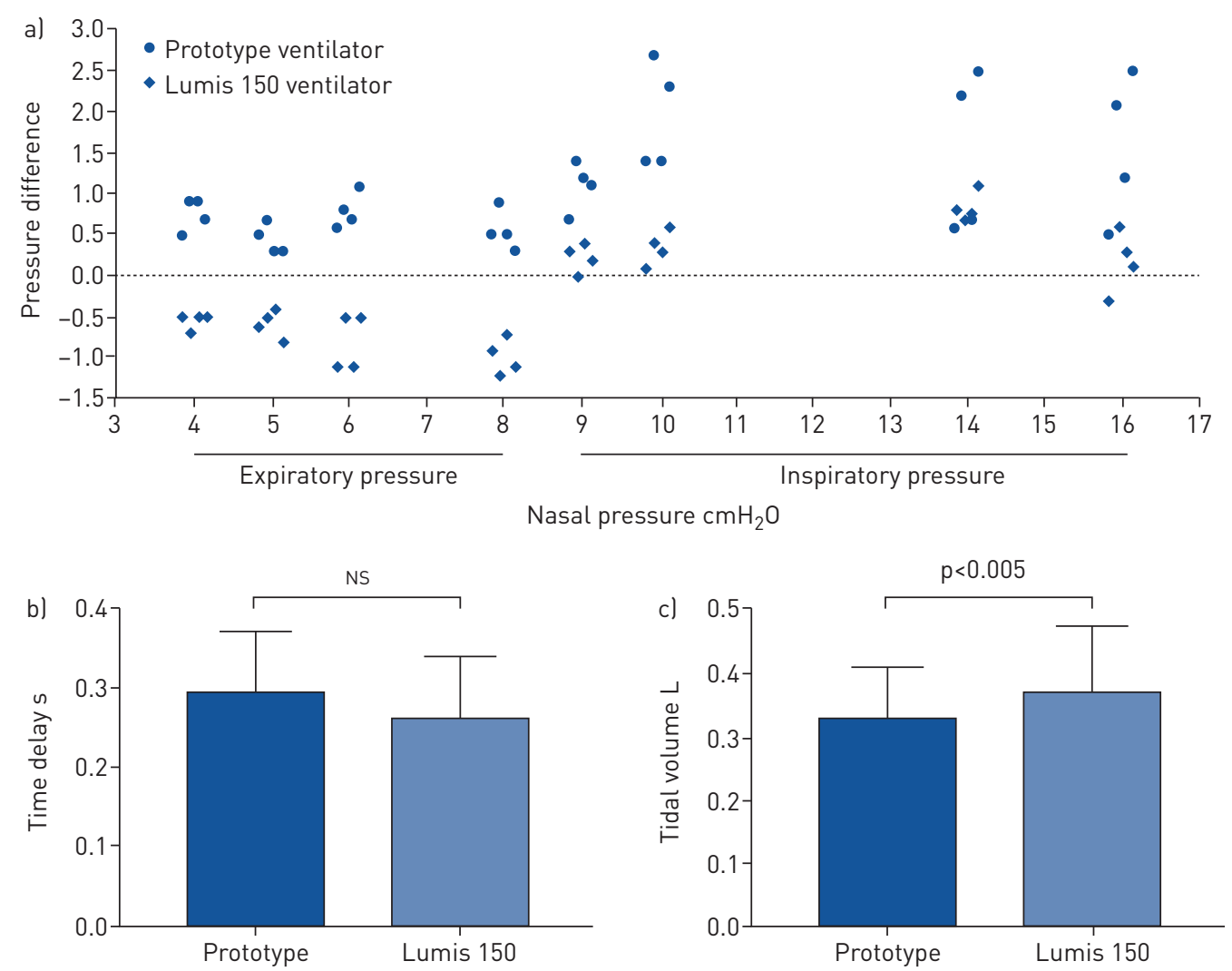

FIGURE 5 a) Pressure difference between (positive peak) inspiratory and (negative peak) expiratory pressures actually delivered by the ventilator and set at the ventilator control panel for both the prototype and Lumis 150 ventilators. b) Inspiratory time delay and c) tidal volume in the prototype and Lumis 150 ventilators. NS: nonsignificant.

(97.0 $\pm 1.3 \%): 96.8 \pm 1.0 \%(\mathrm{p}=0.51)$ and $96.8 \pm 0.9 \%(\mathrm{p}=0.23)$ when supported with the prototype and commercial ventilator, respectively. As shown in figure 6, discomfort scoring when the 12 subjects were subjected to respiratory loading was $5.45 \pm 1.68$. These values significantly decreased to $2.83 \pm 1.66(\mathrm{p}<0.005)$ when the loaded patient's breathing was supported by the prototype ventilator. Interestingly, the relief in breathing difficulty was virtually the same as the one achieved with the high-performance commercial ventilator $(2.80 \pm 1.48 ; \mathrm{p}=1.000)$. No significant differences were observed in the variability across the three measurements of breathing discomfort $(p=0.208$; average SD 0.61). Figure 7 presents an example of the nasal pressure and flow signals when the prototype ventilator, set to considerable values of NIV inspiratory and expiratory pressures, was applied to a loaded-breathing volunteer, illustrating that the

FIGURE 6 Discomfort scoring (Visual Analog Scale) in healthy volunteers subjected to obstructive-restrictive loaded breathing when unsupported and when supported by the prototype and Lumis 150 ventilators.

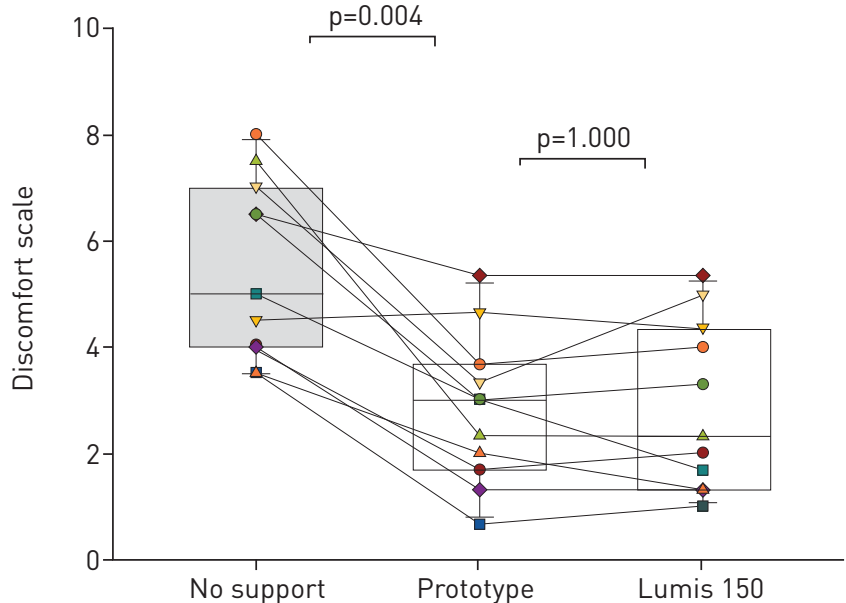



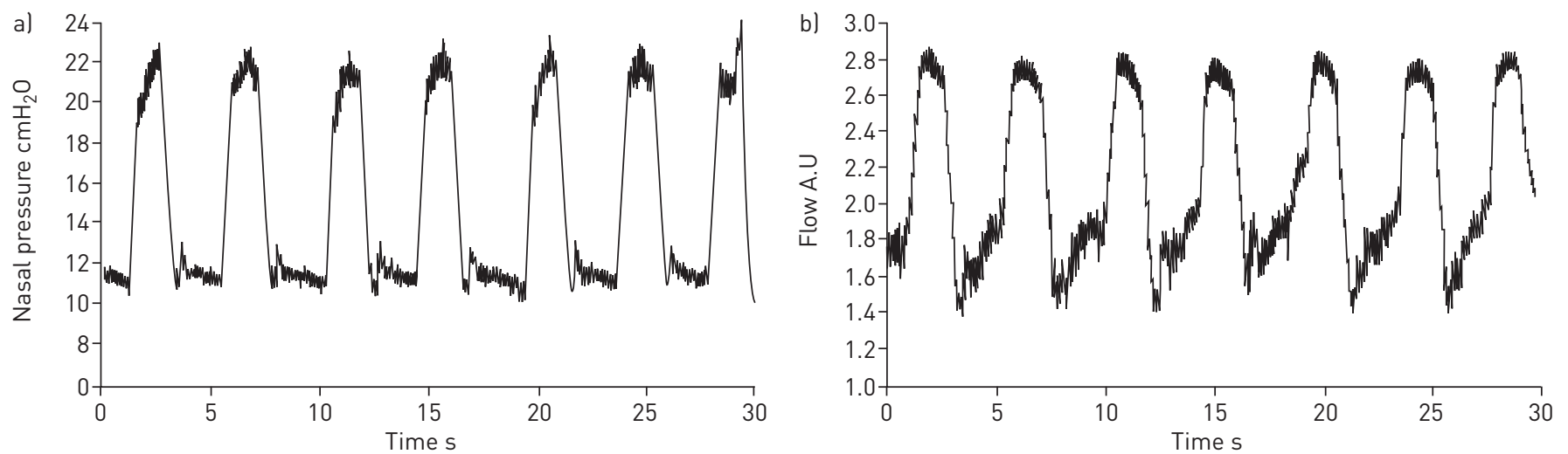

FIGURE 7 Example of a) pressure and b) flow signals recorded when a resistive-restrictive loaded breathing volunteer's breathing was supported by the prototype ventilator. These are unfiltered raw data from the sensors within the ventilator. The flow signal is uncalibrated in both amplitude and zero. A.U: arbitrary units.

pressure waveform was suitable, and that the ventilator smoothly followed the breathing pattern of the subjects since no faulty triggering of cycling was detected. Figure S2 shows that the prototype ventilator was able to trigger mandatory ventilation cycles in case of absence of subject's inspiratory effort.

\section{Discussion}

Herein, we describe a very low-cost bilevel pressure support ventilator which is easy-to-build for potential use in under-resourced areas of developing countries or during pandemic conditions such as those imposed currently by the novel coronavirus on top of already strained hospital conditions dealing with the influenza season. The results obtained during both the bench testing and during the applicability pilot study in humans confirmed that the newly designed low-cost ventilator performs comparably to currently available commercial ventilators. Specifically, the device functioned as expected under stressing conditions in both the bench test (high load impedance and unintended leaks) and in the test with subjects with obstructive-restrictive loaded breathing.

The ventilator is based on a modular structure (figure $1 \mathrm{~b}$ ) requiring only basic electronic training for an overall straightforward and easy assembly. The device modules are interconnected by compact electrical wiring and, therefore, such design enables simple replacement of each module independently, as needed. The setting requires no pre-calibration routines since pressure transducers are thermally corrected, and are provided with factory calibration. Interestingly, when the ventilator is switched on, an automatic routine process automatically tests and digitally corrects any drift in the zero signal of the transducers. Flow is sensed with a pneumotachograph consisting of a slight constriction in the tube section separating the two pressure transducers. As such orifice-like resistor is nonlinear, the pressure drop signal across the transducers is digitally linearised (by computing the square root) in real time. Given that cycling (end inspiration) is determined when inspiratory flow falls below a certain percentage (usually 30-50\% [23], selectable by the user) of the inspiratory peak, the flow signal does not require calibration. In addition to the hardware components, the Arduino code controlling the ventilator (which is also provided open access) can be re-uploaded at any time, thereby allowing for simple updates to the ventilator functions in LMICs, with locally or remotely updated code. For instance, cheap high (or low) pressure acoustic alarms can easily be added. Moreover, the non-linear resistor to estimate flow can be replaced by a linear pneumotachograph to measure flow, and the related inspired volume (although this would increase cost and require periodic calibration). Furthermore, the ventilator control can be adapted to take into account the pressure drop induced by a humidifier in case this component is connected between the ventilator output and the tube connecting to the patient's mask. Of note, the proposed approach for ventilator construction empowers the final users in LMICs to fully control the procedure, to adapt it to the local conditions, and to update the used components in response to market availability. Moreover, continued support from and collaboration with experienced teams abroad is easy and readily feasible. In a time when the most complex devices appear to be needed and can only be provided by a very competitive and specialised industry, the simplicity and performance of this designed low-cost device reminds us of the need to go back to the basics, in as much as the rationale and implementation of NIV has not changed substantially from the pioneering times when this therapy was developed [24].

The bench test was carried out employing a commonly used type of actively breathing patient simulator $[9-11,16,18]$, mimicking a wide spectrum of patient's respiratory mechanical alterations (obstruction 
and/or restriction), and including normal and high breathing frequencies. Moreover, the ventilator was tested under conditions reproducing an unintended leak, a circumstance frequently encountered during clinical NIV practice. The 16 different bench test settings (table 1) used to assess the ventilator covered the wide range of conditions that noninvasive ventilators are exposed to in real-life clinical applications. The bench test showed that, regardless of the stressing test conditions, the prototype ventilator provided the target bilevel pressures (figure 5a) with no faulty triggering or cycling, and with a suitable triggering delay (figure $5 b$ and $c$ ), thereby enabling good synchronisation with the inspiratory effort of the simulated patient. The relative simplicity of the feedback control system in the prototype ventilator explains the slightly different shape of pressure waveform observed over the wide range of test conditions (figure 5a), and also facilitates interpretation of the determinants of the small increases in peak inspiratory pressures. Whereas the commercial device applied an almost square pressure signal, the pressure waveform generated by the prototype exhibited progressive increases and decreases in inspiratory pressures (figure 4 ). This is consistent with the fact that the commercial device used as a comparator was probably equipped with a more powerful (and hence expensive) feedback system to control its blower. However, several other commercially available ventilators exhibit patterns of inspiratory pressures similar to those observed in the prototype (figure $4 \mathrm{a}$ and c) [25]. In fact, the slope of the ramp of increasing inspiratory pressure is one of the parameters that can be set by the user in some commercially available devices, since excessively rapid increases in early onset of inspiratory pressures may lead to patient discomfort (figure $4 \mathrm{~b}$ and $\mathrm{d}$ ) by not mimicking the physiological inspiratory patterns characterised by progressive increases in flow. Although tidal volume was not a direct outcome variable controlled by pressure support ventilators, it is interesting to note that the prototype ventilator resulted in tidal volumes that were similar to the ones generated by the commercial device (figure $5 \mathrm{c}$ ), adding further support to the suitability of the prototype ventilator for generating inspiratory pressure waveforms and adequate tidal volumes in a wide spectrum of simulated patients (table 1).

The applicability pilot study was carried out in healthy volunteers subjected to obstructive and restrictive breathing loads. This model is widely used in the literature to simulate the mechanical load of the respiratory system for investigating ventilation [19-21] and for simulating dyspnoea [26, 27]. In fact, the level of obstruction-restriction we applied to our volunteers resulted in a breathing discomfort score (figure 6) similar to the ones set in recent reports to mimic dyspnoea by loaded breathing [26, 27]. The results obtained when testing the applicability of the prototype ventilator in humans showed that, similar to the bench test, there were no faulty triggering or cycling events, that the pressure waveform was similar to those typically observed in commercial ventilators (figure 7 and figure S2), and that the relief of breathing discomfort was virtually the same as the one achieved by the commercial ventilator (figure 6).

In addition to methodological and technical issues discussed above, the work presented here requires that we specifically address two aspects that are usually lacking in medical device studies: 1) an industrial/ commercial model; and b) safety/ethical issues. Indeed, in this work we propose an alternative procedure for building ventilators in-house and locally, i.e. outside the conventional medical device industrial market. There is little doubt that industry-based conventional production chains, including design, manufacturing and commercialisation, play a key role in the healthcare system. Accordingly, industry heavily invests in Research and Development (R\&D) and translates new knowledge from the laboratory bench to patient bedside. In other words, the medical device industry searches and delivers life-enhancing innovative solutions. Unfortunately, such an industrially based model is hardly suitable to low-income settings that are usually resource scarce, and where the provision of even adequate basic services to the population is challenging. The main reason why the conventional industrial model does not work in LMICs is that the standard industrial production scheme, which also applies to entirely not-for-profit companies, entails significant costs beyond those strictly required for device manufacturing.

The vast majority of medical device companies are small and medium-sized, employing $<50$ people, both in Europe (95\% of all medical technology firms) and in the USA (80\%) [28]. Moreover, those companies, mainly based in USA and Canada (49\% of the world market), Europe (27\%), Japan (7\%) and China (6\%), are highly and globally regulated to guarantee the safety and performance of their innovative and high technology products throughout their life-cycle, as well as pre-and post-marketing [28]. Unlike many other industries, $\mathrm{R} \& \mathrm{D}$ expenditures represent a significant cost component for medical device companies. These companies spend on average between $6 \%$ and $12 \%$ of revenues towards $\mathrm{R} \& \mathrm{D}$ investment [29], with some niche firms or start-ups incurring even higher $\mathrm{R} \& \mathrm{D}$ costs $(>20 \%)$. Average selling, general and administrative expenses, which include marketing, advertising and promotion costs and general and administrative costs, account for about one-third of total revenues [30]. Importantly, the cost of goods sold, which measures the total cost that it takes for a medical device company to manufacture its products including labour, material costs, rental and utility costs, represent between $35 \%$ and $40 \%$ of revenues [30], with the remaining costs going to taxes, interests and depreciation. Thus, a disproportionately large share 
of medical device companies' revenues is slated for expenses beyond those needed to manufacture their products. In contrast, in the approach we describe in this work, as ventilator assembly is performed locally or directly linked to local technical partners, the only costs incurred are those associated with purchasing of the components and the actual labour costs of assembling the device, both of which are low thanks to e-commerce and labour costs in LMICs, respectively. Of note, the approach proposed here may not only allow for adequate availability of ventilators to patients [31-34], but may also contribute to the development of the local industry network in LMICs [35-37].

Regarding safety and ethical issues, it is important to emphasise that the development and testing of the NIV devices that are available on the market nowadays was made possible by the development of devices built in-house by physicians and researchers in developed countries, and that these innovations were designed, tested and improved in patients before the corresponding labelling was obtained [24]. Notwithstanding, the in-house ventilator proposed here does not have the conventional FDA/CE approvals. Obviously, such approval procedures are tremendously important for ensuring that medical devices placed into the market are safe and reliable and, as such, have contributed to the progress currently achieved in healthcare. However, obtaining FDA/CE labels is a process devised mainly for the industry in developed countries and is extremely expensive in terms of LMICs financial resources. Although these countries do not have the complex infrastructure required for such costly processes, simplified or ad-hoc approval procedures could be provided by local authorities or hospital Ethical Boards. However, particularly in light of the non-existent alternative of using industrial ventilators, i.e. leaving the patient untreated with the attendant consequences. Under such difficult circumstances, the ethical trade-off towards compassionate use of medical devices, a mechanism already in place for non-labelled therapies in developed countries, may be considered.

In conclusion, we have designed a low-cost easy-assembly ventilator with excellent performance characteristics in both the bench tests and in voluntary subjects. If, as anticipated, from these preliminary results, clinical field tests are favourable, this low-cost device may enable provision of respiratory support to patients in LMICs who otherwise would have no access to this potentially life-saving therapy, as well as escalation of ventilatory support availability in strenuous circumstances such as those imposed by respiratory virus pandemics.

Conflict of interest: O. Garmendia has nothing to disclose. M.A. Rodríguez-Lazaro has nothing to disclose. J. Otero has nothing to disclose. P. Phan has nothing to disclose. A. Stoyanova has nothing to disclose. A.T. Dinh-Xuan has nothing to disclose. D. Gozal has nothing to disclose. D. Navajas has nothing to disclose. J.M. Montserrat has nothing to disclose. R. Farré has contracts via his institution to evaluate CPAP devices for ResMed and ANTADIR, outside the submitted work.

\section{References}

1 Rochwerg B, Brochard L, Elliott MW, et al. Official ERS/ATS clinical practice guidelines: noninvasive ventilation for acute respiratory failure. Eur Respir J 2017; 50: 1602426.

2 Mandelzweig K, Leligdowicz A, Murthy S, et al. Non-invasive ventilation in children and adults in low- and low-middle income countries: a systematic review and meta-analysis. J Crit Care 2018; 47: 310-319.

3 Murthy S, Leligdowicz A, Adhikari NKJ. Intensive care unit capacity in low-income countries: a systematic review. PLoS One 2015; 10: e0116949.

4 Truog RD, Mitchell C, Daley CQ. The toughest triage - allocating ventilators in a pandemic. N Engl J Med 2020; 50: 3 .

5 Wang $\mathrm{D}, \mathrm{Hu}$ B, Hu C, et al. Clinical characteristics of 138 hospitalized patients with 2019 novel coronavirus-infected pneumonia in Wuhan, China. JAMA 2020; e201585.

6 Howie SRC, Hill SE, Peel D, et al. Beyond good intentions: lessons on equipment donation from an African hospital. Bull World Health Organ 2008; 86: 52-56.

7 Farré R, Trias G, Solana G, et al. Novel approach for providing pediatric continuous positive airway pressure devices in low-income, under resourced regions. Am J Respir Crit Care Med 2019; 199: 118-120.

8 Farré R, Montserrat JM, Solana G, et al. Easy-to-build and affordable continuous positive airway pressure CPAP device for adult patients in low-income countries. Eur Respir J 2019; 53: 1802290.

9 Lujan M, Sogo A, Pomares X, et al. Effect of leak and breathing pattern on the accuracy of tidal volume estimation by commercial home ventilators: a bench study. Respir Care 2013; 58: 770-777.

10 Carteaux G, Lyazidi A, Cordoba-Izquierdo A, et al. Patient-ventilator asynchrony during noninvasive ventilation. Chest 2012; 142: 367-376.

11 Olivieri C, Costa R, Conti G, et al. Bench studies evaluating devices for non-invasive ventilation: critical analysis and future perspectives. Intensive Care Med 2012; 38: 160-167.

12 Farré R, Montserrat JM, Rigau J, et al. Response of automatic continuous positive airway pressure devices to different sleep breathing patterns. Am J Respir Crit Care Med 2002; 166: 469-473.

13 Rigau J, Montserrat JM, Wöhrle H, et al. Bench model to simulate upper airway obstruction for analyzing automatic continuous positive airway pressure devices. Chest 2006; 130: 350-361.

14 Isetta V, Navajas D, Montserrat JM, et al. Comparative assessment of several automatic CPAP devices' responses: a bench test study. ERJ Open Res 2015; 1: 00031-2015. 
15 Isetta V, Montserrat JM, Santano R, et al. Novel approach to simulate sleep apnea patients for evaluating positive pressure therapy devices. PLoS One 2016; 11: e0151530.

16 Farré R, Navajas D, Montserrat JM. Technology for noninvasive mechanical ventilation: looking into the black box. ERJ Open Res 2016; 2: 1-11.

17 Zhu K, Farré R, Katz I, et al. Mimicking a flow-limited human upper airway using a collapsible tube: relationships between flow patterns and pressures in a respiratory model. J Appl Physiol 2018; 125: 605-614.

18 Bunburaphong $\mathrm{T}$, Imanaka $\mathrm{H}$, Nishimura $\mathrm{M}$, et al. Performance characteristics of bilevel pressure ventilators. Chest 1997; 111: 1050-1060.

19 Eberlein M, Schmidt GA, Brower RG. Chest wall strapping. An old physiology experiment with new relevance to small airways diseases. Ann Am Thorac Soc 2014; 11: 1258-1266.

20 Mols G, von Ungern-Sternberg B, Rohr E, et al. Respiratory comfort and breathing pattern during volume proportional assist ventilation and pressure support ventilation: a study on volunteers with artificially reduced compliance. Crit Care Med 2000; 28: 1940-1946.

21 Mols G, Vetter T, Haberthür C, et al. Breathing pattern and perception at different levels of volume assist and pressure support in volunteers. Crit Care Med 2001; 29: 982-988.

22 Ferreira JC, Chipman DW, Kacmarek RM. Trigger performance of mid-level ICU mechanical ventilators during assisted ventilation: a bench study. Intensive Care Med 2008; 34: 1669-1675.

23 Moerer O, Harnisch LO, Herrmann P, et al. Patient-ventilator interaction during noninvasive ventilation in simulated COPD. Respir Care 2016; 61: 15-22.

24 Sullivan CE. Nasal positive airway pressure and sleep apnea. Reflections on an experimental method that became a therapy. Am J Respir Crit Care Med 2018; 198: 581-587.

25 Battisti A, Tassaux D, Janssens JP, et al. Performance characteristics of 10 home mechanical ventilators in pressure-support mode: a comparative bench study. Chest 2005; 127: 1784-1792.

26 Nierat M-C, Demiri S, Dupuis-Lozeron E, et al. When breathing interferes with cognition: experimental inspiratory loading alters timed up-and-go test in normal humans. PLoS One 2016; 11: e0151625.

27 Allard E, Canzoneri E, Adler D, et al. Interferences between breathing, experimental dyspnoea and bodily self-consciousness. Sci Rep 2017; 7: 9990.

28 MedTech Europe. The European Medical Technology Industry - in figures 2019. www.medtecheurope.org/ wp-content/uploads/2019/04/The-European-Medical-Technology-Industry-in-figures-2019-2.pdf Date last accessed: 24 March 2020.

29 Spence P, Babitt J, Welch J, et al. As change accelerates, how can medtechs move ahead and stay there? Pulse of the industry 2017. www.ey.com/Publication/vwLUAssets/ey-as-change-accelerates-how-can-medtechs-move-aheadand-stay-there/\$FILE/ey-as-change-accelerates-how-can-medtechs-move-ahead-and-stay-there.pdf Date last accessed: 24 March.

30 Fuhr T, George K, Pai J. The business case for medical device quality. www.mckinsey.com/ /media/McKinsey/ dotcom/client_service/Public\%20Sector/Regulatory\%20excellence/The_business_case_for_medical_device_quality.ashx Date last accessed: 24 March 2020.

31 Pearce JM. Quantifying the value of open source hardware development. Modern Econ 2015; 6: 1-11.

32 Pearce JM. Maximizing returns for public funding of medical research with open-source hardware. Health Policy Technol 2017; 6: 381-382.

33 Eslambolchilar P, Thimbleby H. Open-source hardware for medical devices. BMJ Innov 2016; 2: 78-83.

34 DePasse JW, Caldwell A, Santorino D, et al. Affordable medical technologies: bringing value-based design into global health. BMJ Innov 2016; 2: 4-7.

35 Mackintosh M, Tibandebage P, Karimi Njeru M, et al. Rethinking health sector procurement as developmental linkages in East Africa. Soc Sci Med 2018; 200: 182-189.

36 De Maria C, Mazzei D, Ahluwalia A. Open source biomedical engineering for sustainability in African healthcare: combining academic excellence with innovation. Proceedings of the ICDS, The Eighth International Conference on Digital Society, 2014; 48-53.

37 Clifford KL, Zaman MH. Engineering, global health, and inclusive innovation: focus on partnership, system strengthening, and local impact for SDGs. Glob Health Action 2016; 9: 30175. 